\title{
Planting depth - effective agricultural practice perventing lodging of seedstalks of onion seeds
}

\author{
$V E$ Lazko $^{1, *}$, and $O V$ Yakimova $^{1}$ \\ ${ }^{1}$ Federal Scientific Rice Centre, Belozerny village, 3, Krasnodar, Russian Federation, 350921
}

\begin{abstract}
At the breeding site of the winter onion variety Ellan, the effect of the planting depth of mother bulbs of two fractions on lodging of stems and seed productivity was studied. It was found that in winter, with the depth of planting the bulbs in the soil horizon, the processes of differentiation and the formation of microstalks noticeably slow down, and the biochemical composition of the bulbs shows a decrease in the activity of metabolic processes. Thanks to this and the buffering properties of the soil, the safety of plants in winter is very high when planted to a depth of $15 \mathrm{~cm}$. Deeper planting has a negative effect on the growth of leaves. At a planting depth of $15-20 \mathrm{~cm}$, the stems remain upright due to the soil layer. The angle of inclination of $82 \ldots 86 \%$ of the stems is not more than 450 and occupies no more than $50 \mathrm{~cm}$ of the width of the projection of the row. When planted to a depth of $10 \mathrm{~cm}$, the stems crumble, agronomic measures, the phytosanitary state of seed production and harvesting are hampered. It was found that the effect of bulb size on seed productivity of one stem is $42 \%$. The increase in planting for the yield of one plant and the yield is $44 \ldots 45 \%$. When setting seed onions, it is recommended to plant uterine bulbs to a depth of $15 \mathrm{~cm}$. This planting depth ensures the maximum safety of the bulbs in winter, excludes lodging of the stems and the maximum possible seed yield. There is no need for additional hilling or tying of the stems, as with a planting depth of $10 \mathrm{~cm}$.
\end{abstract}

\section{Introduction}

Agricultural technology on the seed production plots of onions should be aimed at creating the best conditions for the development of plants and the formation of a high-quality seed yield. One of the reasons for the decline in productivity and the deterioration of the phytosanitary condition is the collapse of seedstalks of the seed nests. Onion seedstalks grow at an angle to the center of the plant. The divergence of seedstalks begins actively from the middle of the flowering phase. During this period, seedstalks fall and easily break off under the weight of the inflorescences. Fallen stalks make soil care and harvesting difficult. Due to the worsening conditions of ventilation and gas exchange, plants are more damaged by peronosporosis and anthracnosis [1-4].

To maintain seedstalks in a vertical position, the plants are spudded to a height of 8-10 $\mathrm{cm}$ after regrowth and secondarily after 20-25 days. In small areas, plants are tied to stakes

\footnotetext{
* Corresponding author: lazko62@mail.ru
} 
or umbels of different plants are tied. Around the ridges make a harness of poles at a height of 0.7-0.8 $\mathrm{m}$ from the ground or pull the trellis. Carrying out these agricultural activities requires significant additional labor costs and materials. Changing the depth of planting, you can influence the lodging of plants when growing them without earthing up and additional supports. Also, the preservation of plants during the wintering period largely depends on the depth of planting. It is generally recommended to be planted to a depth of 6$7 \mathrm{~cm}$. With a shallow embedment, the bulbs rise on the roots above the ground, the roots dry out. Such bulbs are easily damaged at low temperatures and overwinter much worse than buried and spoiled soil layers [5-10].

The aim of the research: to determine how the planting depth affects the physiological and biochemical processes in the bulbs, the safety in winter, the growth rate during the growing season, the decay of the bush and the lodging of seedstalks.

\section{Materials and methods}

The studies were carried out in the central zone of Krasnodar region at the experimentalbreeding plot of the vegetable and potatobreeding department of the Federal State Budgetary Scientific Institution "Federal Scientific Rice Centre" according to the generally accepted methodology [2]. The soil and climatic conditions of the zone allow conducting seed production of onions in wintertime. Mother bulbs of the early winter short-day variety Ellan of two fractions were used for laying the experiment: medium - $50 \mathrm{~g}$ and small $-30 \mathrm{~g}$. The bulbs were planted in the second decade of November in previously cut grooves to a depth of 10, 15 and $20 \mathrm{~cm}$. Planting pattern $0.7 \times 0.1 \mathrm{~m}$. Planting density of 143 thousand units / ha. During the growing season, phenological and biometric observations and counts were carried out [2]. V.A. Dzyuba [10,11] and A.Kh carried out statistical processing of the results according to methodological recommendations. Sheudzhen [9, 12]. The technology used to grow onion seeds was generally accepted in Krasnodar region for onion varieties [13-15].

\section{Results of research}

At different planting depths, growth buds and the root system are located vertically in the arable horizon under conditions of different temperature and humidity, which significantly influenced the physiological and biochemical processes in the bulbs. Two months after planting, mother bulbs had a developed root system, which consisted mainly of string-like roots without branches. The number and length, which depended on the depth of landing. With an increase in the depth of bulb placement along the soil profile, the number of roots significantly decreased (table 1). But the more roots grew in plants, the less was their length. In the fall, before the start of a steady cooling, leaf growth began in bulbs planted to a depth of $10 \mathrm{~cm}$. The number of bulbs with sprouting leaves and their length depended on the depth of planting, the less the depth of planting was, the more bulbs grew and the length of the leaves. In most bulbs, the differentiation of vegetative buds into generative ones began. Analysis of the sections of the bottoms showed that the maximum number of buds with microstalks $(88 \%)$ was formed in bulbs planted to a depth of $10 \mathrm{~cm}$. With an increase in the depth of planting, the number of bulbs that passed the vernalization stage decreased. Similar results of biometric analysis were obtained in small fraction bulbs. 
Table 1. Biometric indicators of onion mother bulbs at different planting depths (2004, middle fraction).

\begin{tabular}{|c|c|c|c|c|}
\hline \multirow[b]{2}{*}{$\begin{array}{l}\text { Planting depth, } \\
\mathrm{cm}\end{array}$} & \multicolumn{2}{|c|}{ Length, $\mathrm{cm}$} & \multicolumn{2}{|c|}{ Number } \\
\hline & roots & $\begin{array}{c}\text { leaf sprout in the } \\
\text { soil }\end{array}$ & roots, pcs. & $\begin{array}{c}\text { buds with } \\
\text { microstalks, } \%\end{array}$ \\
\hline 10 & $10-20$ & $7-10$ & $60-100$ & 88 \\
\hline 15 & $13-21$ & $0-7$ & $48-73$ & 80 \\
\hline 20 & $15-23$ & $0-5$ & $25-62$ & 65 \\
\hline & $\begin{array}{r}\mathrm{F} \\
\text { For } \\
\mathrm{F} \\
\text { For } \mathrm{m}\end{array}$ & $\begin{array}{l}\text { length } F_{\text {fact. }} 26,00 \\
\text { out length } F_{\text {fact. }} 8, \\
\text { umber } F_{\text {fact. }} 49,63 \\
\text { s number } F_{\text {fact. }} 20\end{array}$ & $\begin{array}{l}\text { al. } 7,71 \\
\text { ritical. } 7,71 \\
\text { cal.7,71 } \\
F_{\text {critical. } 7,71}\end{array}$ & \\
\hline
\end{tabular}

In the bulbs of all experimental variants throughout the winter period, new roots continued to grow. The growth rate and the concentration zone of the bulk of the roots decreased vertically in the arable horizon with increasing planting depth. With freezing of the soil, the roots of the bulbs planted to a depth of $10 \mathrm{~cm}$ were frozen first to the depth of the root layer. With the increase in the depth of planting of mother bulbs, the number of roots damaged by frost decreased, as the temperature fluctuations in the soil were smoothed out with depth.

The biochemical composition of the bulbs changed with planting depth and depended on the rate of vegetative growth and the transition to the reproductive phase. With an increase in planting depth, the activity of disacchar decomposition decreased and the loss of dry soluble substances (DSS) used for growth processes and generative transformations in plants decreased (table 2). The maximum number of monosugars $(90.5 \%)$ was contained in the bulbs at the smallest planting. Similar results were obtained in the analysis of the small fraction of the bulbs. Thus, with an increase in the depth of planting of mother bulbs, biochemical indices, as well as morphological ones, indicated a slowdown in plant growth and weakened metabolic processes in them, making them less vulnerable to adverse winter conditions. This was reflected in the winter hardiness of mother onion plants.

Severe weather conditions in the winter of 2002-2003 showed that the best conditions for overwintering were found in mother bulbs planted to a depth of $15 \mathrm{~cm}$. By the spring growing season, all branches of the plant were preserved. With a small planting $(10 \mathrm{~cm})$, losses during the winter amounted to $4 \%$ of the bulbs. A deep landing $(20 \mathrm{~cm})$ was critical for weakened bulbs, in the spring $4 \%$ did not rise. The weather conditions of the winter of 2003-2004 and 2004-2005 were generally favorable for the wintering of mother bulbs. Air temperature rarely dropped to minus 10 degrees. The soil froze to a depth of 5-7 cm. Frosty periods lasted no more than 2-4 days. Losses of bulbs planted at different depths were only from diseases within $1-2 \%$.

Table 2. Biochemical composition of mother bulbs at different planting depths. (January 2004, medium fraction).

\begin{tabular}{|c|c|c|c|c|c|c|}
\hline \multirow{2}{*}{$\begin{array}{l}\text { Planting } \\
\text { depth, } \\
\mathrm{cm}\end{array}$} & \multirow{2}{*}{$\begin{array}{c}\text { DSS, } \\
\%\end{array}$} & \multicolumn{3}{|c|}{ Sugars, $\%$} & \multirow{2}{*}{$\begin{array}{l}\text { Monosugars in } \\
\text { the } \% \text { from the } \\
\text { sum }\end{array}$} & \multirow{2}{*}{$\begin{array}{c}\text { Ascorbic } \\
\text { acid, mg \% }\end{array}$} \\
\hline & & Sum & Disugars & Monosugars & & \\
\hline 10 & 7,49 & 3,57 & 0,70 & 3,23 & 90,5 & 12,13 \\
\hline 15 & 7,50 & 4,30 & 0,85 & 3,45 & 80,2 & 10,87 \\
\hline 20 & 8,02 & 4,34 & 1,14 & 3,10 & 71,4 & 9,62 \\
\hline \multicolumn{7}{|c|}{$\begin{array}{l}\text { For DSS F Fact. } 0,16<\mathrm{F}_{\text {critical. }} 5,14 \\
\text { or sum of sugars } \mathrm{F}_{\text {fact. }} 0,07<\mathrm{F}_{\text {critical. }} 5,14 \\
\text { For disugars } \mathrm{F}_{\text {fact. }} 9,03>\mathrm{F}_{\text {critical. }} 5,14 \\
\text { For disugars } L S D_{05} 0,13 \\
\text { or monosugars } \mathrm{F}_{\text {fact. }} 0,02<\mathrm{F}_{\text {critical. }} .14\end{array}$} \\
\hline
\end{tabular}


Planting depth directly affected the passage of phenological phases by onion plants. In spring, bulbs of small and medium fractions grew earlier than others from a depth of $10 \mathrm{~cm}$. They grew with a delay of 2-4 days from a depth of $15 \mathrm{~cm}$ and sprouts appeared on bulbs planted to a depth of $20 \mathrm{~cm} \mathrm{5-6} \mathrm{days} \mathrm{later} \mathrm{(fig.} \mathrm{1).}$

The timing of seedstalks was influenced by weather conditions. In the cold spring of 2003, the start of shooting was noted at the end of the first decade of May, in plants planted to a depth of 10-15 cm. In the warm spring of 2004 and 2005, seedstalks began to appear a week earlier in the same planting variants. Plants from small fraction bulbs were late with stalks for 4-6 days. The number of shoot plants by observation dates decreased with increasing planting depth. Plants entered the shooting phase within 8-10 days. Seedstalks continued to appear for 7-10 days (table 3).

Table 3. Dynamics of the shooting of onion seeds of medium and small fractions at different planting depths over two years.

\begin{tabular}{|c|c|c|c|c|c|c|c|}
\hline \multirow{2}{*}{$\begin{array}{l}\text { Planting } \\
\text { depth, } \\
\text { cm }\end{array}$} & \multicolumn{7}{|c|}{ Date of accounting } \\
\hline & 11.05 & 14.05 & 16.05 & 17.05 & 19.05 & 22.05 & 25.05 \\
\hline \multicolumn{8}{|c|}{2003} \\
\hline \multicolumn{8}{|c|}{ Medium fraction } \\
\hline 10 & $12^{\mathrm{a}} \backslash 6^{\mathrm{b}}$ & $52 \backslash 35$ & $92 \backslash 65$ & $93 \backslash 73$ & $96 \backslash 89$ & $100 \backslash 97$ & 100 \\
\hline 15 & $12 \backslash 5$ & $48 \backslash 35$ & $84 \backslash 65$ & $88 \backslash 71$ & $92 \backslash 82$ & $100 \backslash 96$ & 100 \\
\hline 20 & $12 \backslash 4$ & $40 \backslash 23$ & $69 \backslash 40$ & $78 \backslash 55$ & $94 \backslash 77$ & $100 \backslash 94$ & 100 \\
\hline \multicolumn{8}{|c|}{ Small fraction } \\
\hline 10 & $6 \backslash 3$ & $47 \backslash 36$ & 91.164 & $98 \backslash 75$ & $100 \backslash 86$ & $100 \backslash 88$ & 100 \\
\hline 15 & 0 & $34 \backslash 24$ & $68 \backslash 47$ & $78 \backslash 60$ & $92 \backslash 84$ & $100 \backslash 96$ & 100 \\
\hline 20 & 0 & $22 \backslash 16$ & $44 \backslash 32$ & $56 \backslash 41$ & $78 \backslash 59$ & $96 \backslash 92$ & 100 \\
\hline \multicolumn{8}{|c|}{2004} \\
\hline & 28.04 & 3.05 & 5.05 & 8.05 & 16.05 & 19.05 & \\
\hline \multicolumn{8}{|c|}{ Medium fraction } \\
\hline 10 & $18 \backslash 12$ & $74 \backslash 47$ & $77 \backslash 52$ & $93 \backslash 77$ & $100 \backslash 97$ & 100 & 100 \\
\hline 15 & 0 & $3 \backslash 1$ & $52 \backslash 29$ & $76 \backslash 58$ & $100 \backslash 95$ & 100 & 100 \\
\hline 20 & 0 & 0 & $14 \backslash 6$ & $43 \backslash 27$ & $96 \backslash 79$ & $100 \backslash 93$ & 100 \\
\hline \multicolumn{8}{|c|}{ Small fraction } \\
\hline 10 & 0 & $3 \backslash 1$ & $29 \backslash 16$ & $84 \backslash 72$ & $100 \backslash 91$ & 100 & 100 \\
\hline 15 & 0 & 0 & $17 \backslash 11$ & $67 \backslash 53$ & $93 \backslash 91$ & 100 & 100 \\
\hline 20 & 0 & 0 & $17 \backslash 11$ & $46 \backslash 38$ & $97 \backslash 80$ & $100 \backslash 92$ & 100 \\
\hline \multicolumn{8}{|c|}{$\begin{array}{l}{ }^{a} \text { Numerator }- \text { number of bushes with seedstalks in percentage terms } \\
{ }^{b} \text { Nominator - number of seedstalks on bushes in percentage terms }\end{array}$} \\
\hline
\end{tabular}




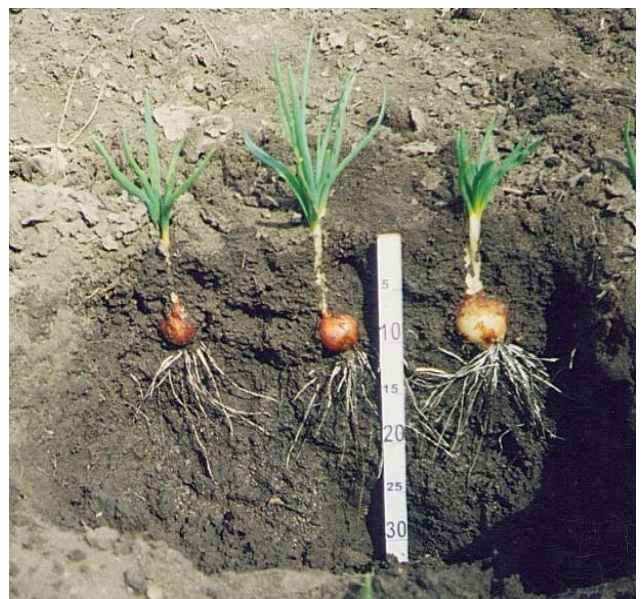

(a) planting depth $10 \mathrm{~cm}$

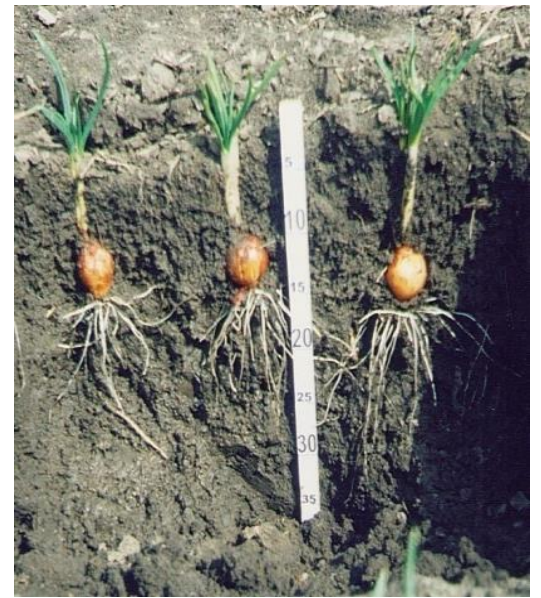

(b) planting depth $15 \mathrm{~cm}$

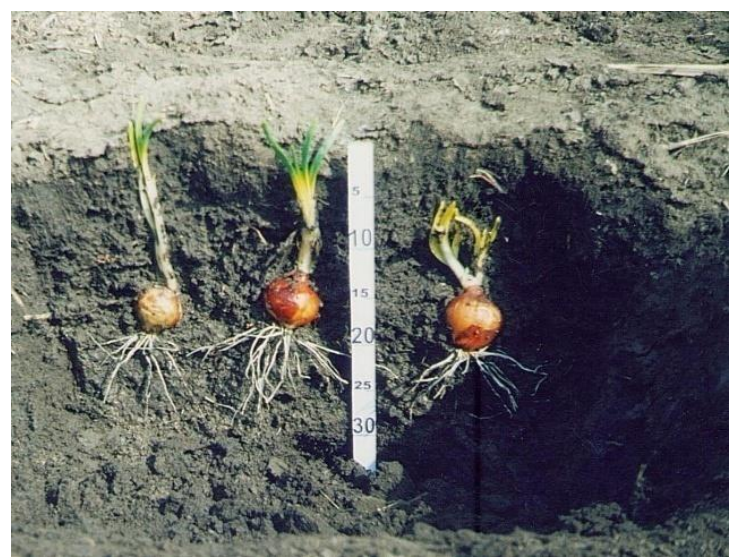

(c) planting depth $20 \mathrm{~cm}$

Fig. 1. Onion plants in the phase of leaf regrowth at different planting depths, (medium fraction), March 2005.

The depth of mother bulbs and their size influenced the formation of the assimilation apparatus of the mother plants. The number of leaves and their sizes decreased with increasing embedment depth (table 4). This tendency persists until the budding phase - the opening of the cover leaf. Then the drying of the leaves began, regardless of the size of the planting material and the depth of embedment. The plants of bulbs of the medium fraction had the greatest parameters of the leaf apparatus, but their assimilation ended earlier, in the first ten days of July, when the flowering phase ended. The leaves of plants from a small fraction of bulbs had smaller parameters and leaf area, the maximum size reached before flowering. During flowering, the leaf apparatus gradually decreased, but remained during seed filling. 
Table 4. Indicators of plant leaf parameters at different planting depths.

\begin{tabular}{|c|c|c|c|c|c|c|c|c|c|}
\hline \multirow{2}{*}{ 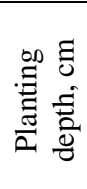 } & \multicolumn{2}{|c|}{$\begin{array}{c}\text { Number } \\
\text { of leaves, } \\
\text { pcs. }\end{array}$} & \multicolumn{4}{|c|}{ Length of leaves, $\mathrm{cm}$} & \multicolumn{3}{|c|}{ Width of leaves, $\mathrm{cm}$} \\
\hline & 2003 & 2004 & 2005 & 2003 & 2004 & 2005 & 2003 & 2004 & 2005 \\
\hline \multicolumn{10}{|c|}{ Medium fraction } \\
\hline & 24 & 37.5 & 25.8 & $11-43$ & $20-47$ & $23-50$ & $1.2-1.6$ & $1.1-1.9$ & $1.4-1.6$ \\
\hline 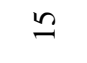 & 22.5 & 36.4 & 22.6 & $11-43$ & $21-45$ & $22-48$ & $1.2-1.7$ & $1.4-2.2$ & $1-1.5$ \\
\hline ㄱ. & 13 & 29.2 & 21.4 & $16-42$ & $19-41$ & $20-41$ & $1.3-1.5$ & $1.3-1.6$ & $1-1.5$ \\
\hline \multicolumn{10}{|c|}{ Small fraction } \\
\hline 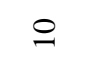 & 18 & 35.3 & 16 & $11-43$ & $19-50$ & $13-50$ & $1.1-1.4$ & $0.9-1.6$ & $1-1.8$ \\
\hline 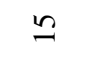 & 15.2 & 33.4 & 15.4 & $16-42$ & $20-50$ & $10-48$ & $1-1.5$ & $1.2-1.7$ & $1-1.5$ \\
\hline ి & 16.2 & 30.3 & 15 & $12-42$ & $12-50$ & $9-42$ & $1.1-1.4$ & $1.3-1.7$ & $1.2-1.5$ \\
\hline
\end{tabular}

After drying of the leaves by the end of flowering, the formation, filling and ripening of onion seeds occurred due to the photosynthetic activity of seedstalks, which served as a leaf. In plants from medium fraction bulbs, the assimilation surface of stalks was $465 \ldots$ $500 \mathrm{~cm}^{2}$ and decreased with the planting depth. The area of seedstalks in plants from small fraction is $4-14 \%$ less than in medium fraction. During the observation period in 2004, favorable weather conditions for temperature and humidity were formed. The area of stalks on plants was 2.1-2.5 times larger in both fractions in all experimental variants, compared with the previous two years (table 5). The depth of planting of mother bulbs influenced in 2003 and 2005 the height of the seedstalks in plants from small fraction, it decreases from a depth of 10 to $20 \mathrm{~cm}$ from 88 to $77 \mathrm{~cm}$. In plants of medium fraction, the height of seedstalks was the same $-84 \ldots 86 \mathrm{~cm}$. In seedstalks in 2004 at different planting depths, 
there were no differences. In plants from bulbs of medium fraction, the height was $109 \ldots$ $111 \mathrm{~cm}$, in the small fraction $-107 \ldots 109 \mathrm{~cm}$.

Table 5. Assimilation surface of onion seed plants at different planting depths.

\begin{tabular}{|c|c|c|c|c|c|c|c|c|}
\hline \multirow{3}{*}{$\begin{array}{l}\text { Planting } \\
\text { depth, cm }\end{array}$} & \multicolumn{6}{|c|}{ Area of the leaves, $\mathrm{cm}^{2}$} & \multicolumn{2}{|c|}{$\begin{array}{c}\text { Area of the } \\
\text { seedstalks, } \mathrm{cm}^{2}\end{array}$} \\
\hline & \multicolumn{8}{|c|}{ Date of accounting } \\
\hline & 10.04 & 27.04 & 15.05 & 04.06 & 24.06 & 10.07 & 04.06 & 03.07 \\
\hline \multicolumn{9}{|c|}{2003} \\
\hline \multicolumn{9}{|c|}{ Medium fraction } \\
\hline 10 & 56 & 292 & 990 & 943 & 423 & 0 & 449 & 500 \\
\hline 15 & 38 & 257 & 926 & 909 & 409 & 0 & 411 & 478 \\
\hline 20 & 27 & 212 & 742 & 800 & 360 & 0 & 400 & 465 \\
\hline \multicolumn{9}{|c|}{ Small fraction } \\
\hline 10 & 31 & 160 & 619 & 705 & 585 & 490 & 411 & 480 \\
\hline 15 & 20 & 116 & 529 & 585 & 505 & 450 & 385 & 455 \\
\hline 20 & 12 & 96 & 503 & 569 & 469 & 300 & 285 & 400 \\
\hline \multicolumn{9}{|c|}{2004} \\
\hline & 21.03 & 11.04 & 3.05 & 30.05 & 23.06 & - & 14.06 & 3.07 \\
\hline \multicolumn{9}{|c|}{ Medium fraction } \\
\hline 10 & 58 & 243 & 771 & 1171 & 720 & - & 700 & 1050 \\
\hline 15 & 47 & 203 & 694 & 1091 & 810 & - & 712 & 1112 \\
\hline 20 & 22 & 154 & 620 & 779 & 700 & - & 750 & 1192 \\
\hline \multicolumn{9}{|c|}{ Small fraction } \\
\hline 10 & 30 & 155 & 440 & 642 & 440 & - & 780 & 840 \\
\hline 15 & 19 & 107 & 408 & 670 & 570 & - & 736 & 1000 \\
\hline 20 & 21 & 110 & 456 & 595 & 504 & - & 814 & 1000 \\
\hline
\end{tabular}

Starting from the flowering phase, the mass of inflorescences increased significantly. The seed nest is prone to falling apart stalks, since peduncles grew at an angle to the center of the plant. The seedstalks began to deviate and fall, intertwining with neighboring rows and often fell to the ground. This significantly worsened the ventilation of the rows, making it difficult to carry out agricultural activities and harvesting. Inflorescences lying on the ground were practically not pollinated by insects, which led to a loss of seed yield. The data obtained had shown that with the deep planting it is possible to exclude seedstalks lodging and grow onion seed plants without hilling (table 6). By the time of harvesting, the planting depth had an impact on the position of seedstalks in the row. The maximum deviation of the seedstalks was in plants planted to a depth of $10 \mathrm{~cm}$. Vertically growing peduncles for harvesting remained $11-19 \%$. The number of seedstalks having a deflection angle of up to 450 was $18 \ldots 37 \%$. Almost half of the stalks deviated by an angle of more than $450-41 \ldots 54 \%$ and touched the ground $-9 \ldots 11 \%$ of the arrows. With a planting depth of $15 \mathrm{~cm}, 31 \ldots 35 \%$ of shooters kept an upright position. Significantly more seedstalks had a deflection angle of not more than $45^{\circ} 43 \ldots 57 \%$. The number of stalks that deviated by an angle of more than $45^{\circ}$ did not exceed $12 \ldots 22 \%$. At such a depth of planting, there were no peduncles intertwined with adjacent rows and touching the ground. With a planting depth of $20 \mathrm{~cm}$, the collapse of the onion seed nest was completely excluded. In the series, the stalk was composed of straight seedstalks $-62 \ldots 68 \%$ and no more than a third of the stalks deviated at an angle of up to $45^{\circ}(32 \ldots 38 \%)$. 
Table 6. Influence of planting depth of onion mother bulbs on the deviation and lodging of seedstalks (average for 3 years).

\begin{tabular}{|c|c|c|c|}
\hline $\begin{array}{l}\text { Planting } \\
\text { depth, } \\
\text { cm }\end{array}$ & $\begin{array}{c}\text { Angle of } \\
\text { seedstalks } \\
\text { deviation on } \\
\text { vertical } \\
\end{array}$ & Number of seedstalks, $\%$ & $\begin{array}{l}\text { Plant stand width } \\
\text { before harvesting, } \mathrm{cm}\end{array}$ \\
\hline \multicolumn{4}{|c|}{ Medium fraction } \\
\hline \multirow{4}{*}{10} & Straight & 11 & \multirow{4}{*}{90} \\
\hline & Up to $45^{\circ}$ & 37 & \\
\hline & More than $45^{\circ}$ & 41 & \\
\hline & On the ground & 11 & \\
\hline \multirow{4}{*}{15} & Straight & 31 & \multirow{4}{*}{60} \\
\hline & Up to $45^{\circ}$ & 57 & \\
\hline & More than $45^{\circ}$ & 12 & \\
\hline & On the ground & 0 & \\
\hline \multirow{4}{*}{20} & Straight & 62 & \multirow{4}{*}{50} \\
\hline & Up to $45^{\circ}$ & 38 & \\
\hline & More than $45^{\circ}$ & 0 & \\
\hline & On the ground & 0 & \\
\hline \multicolumn{4}{|c|}{ Small fraction } \\
\hline \multirow{4}{*}{10} & Straight & 19 & \multirow{4}{*}{100} \\
\hline & Up to $45^{\circ}$ & 18 & \\
\hline & More than $45^{\circ}$ & 54 & \\
\hline & On the ground & 9 & \\
\hline \multirow{4}{*}{15} & Straight & 35 & \multirow{4}{*}{50} \\
\hline & Up to $45^{\circ}$ & 43 & \\
\hline & More than $45^{\circ}$ & 22 & \\
\hline & On the ground & 0 & \\
\hline \multirow{4}{*}{20} & Straight & 68 & \multirow{4}{*}{35} \\
\hline & Up to $45^{\circ}$ & 32 & \\
\hline & More than $45^{\circ}$ & 0 & \\
\hline & On the ground & 0 & \\
\hline
\end{tabular}

An analysis of the results showed that with a decrease in the planting depth, the projection width of the row plant stand increased. So, the row projection width at a planting depth of $20 \mathrm{~cm}$ in the small fraction did not exceed $30 \ldots 35 \mathrm{~cm}$ (fig. 2, c), in the middle fraction no more than $50 \mathrm{~cm}$. When the planting depth was $15 \mathrm{~cm}$, the row plant stand width was within $50 \ldots 60 \mathrm{~cm}$ (fig. 2, b). And the greatest deviation of the seedstalks from the vertical position was at the depth of planting bulbs by $10 \mathrm{~cm}$. Here, the width of the row projection was $90 \ldots 100 \mathrm{~cm}$. The seedstalks intertwined with the neighboring rows, making it difficult for plants to continue to go and to harvest inflorescences (fig. 2, a).

Counting the number of seedstalks that deviated beyond the projection of the row obtained with a landing depth of $20 \mathrm{~cm}(50 \mathrm{~cm}$ in the medium fraction and $30 \mathrm{~cm}$ in the small fraction) showed that $82 \ldots 86 \%$ of seedstalks were in the zone of this projection with a planting depth of $15 \mathrm{~cm}$. With a planting depth of $10 \mathrm{~cm}$, less than half - $46 \ldots 47 \%$. Consequently, with a shallow planting without earthing up rows, 53-54\% of shooters occupied the area of another row, making it difficult to care for and harvest.

The yield of seed plants depends on the number of plants harvested, the number of seedstalks on them and their seed productivity (table 7). A greater number of seedstalks 
formed on plants from medium-sized bulbs. The number of arrows on the plant is greater at a planting depth of $15-20 \mathrm{~cm}$ and higher on plants of the middle fraction. With a landing depth of $10 \mathrm{~cm}$, the number of arrows is slightly less due to their falling and breaking off.

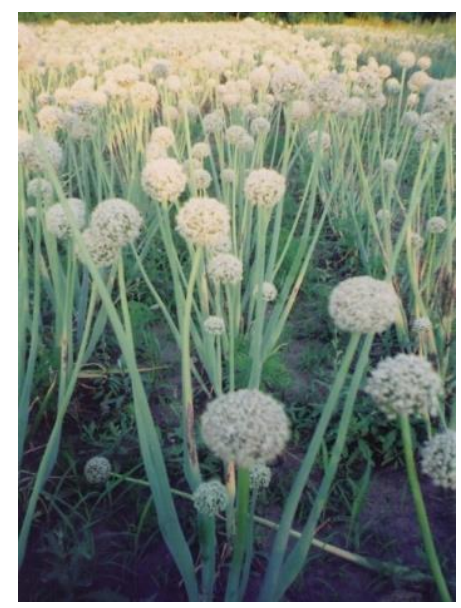

(a) planting depth $10 \mathrm{~cm}$

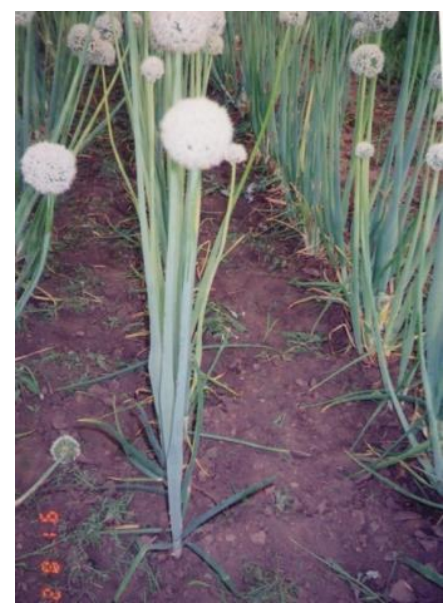

(c) planting depth $20 \mathrm{~cm}$

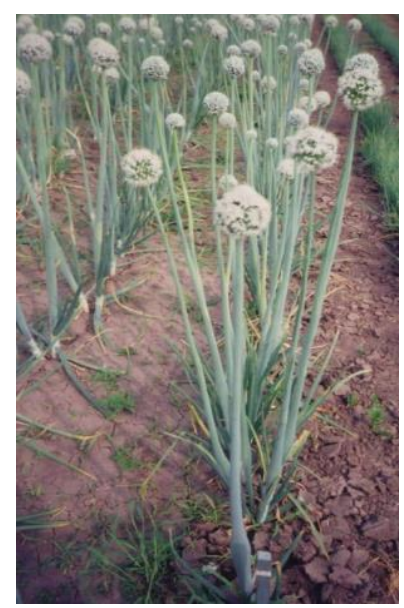

(b) planting depth $15 \mathrm{~cm}$

Fig. 2. Effect of planting depth on the plant stand width and deviation of the seedstalks (flowering phase).

The yield of the seedstalk in the medium fraction is approximately the same (2.64-2.72 $\mathrm{g})$, in the small fraction is higher with a planting depth of $15-20 \mathrm{~cm}(2.97-3.07 \mathrm{~g})$. Seedstalk yield with shallow planting $(10 \mathrm{~cm})$ is less due to losses from under-pollination of fallen stalks and their partial crumbling. The yield of seeds from the plant in both fractions is higher with a planting depth of 15-20 $\mathrm{cm}(8.76-8.93 \mathrm{~g}$ in the medium fraction and less 7.45-7.81 $\mathrm{g}$ in the small fraction). 
Table 7. Indicators of the seed yield at different planting depths of mother bulbs (average for 3 years).

\begin{tabular}{|c|c|c|c|c|c|c|c|c|}
\hline \multirow[b]{2}{*}{$\begin{array}{l}\text { Planting } \\
\text { depth, cm }\end{array}$} & \multicolumn{2}{|c|}{ Plants, $\%$} & \multirow{2}{*}{$\begin{array}{c}\text { Seedstalks } \\
\text { on } 1 \text { bush, } \\
\text { pcs }\end{array}$} & \multicolumn{2}{|c|}{ Mass of the seeds } & \multirow[b]{2}{*}{$\begin{array}{l}\text { Yield, } \\
\mathrm{kg} / \mathrm{ha}\end{array}$} & \multicolumn{2}{|c|}{$\begin{array}{l}\text { Bulbs near the } \\
\text { seedstalk }\end{array}$} \\
\hline & Overwintered & Harvested & & $\begin{array}{c}\text { From } 1 \\
\text { seedstalk, } \\
\mathrm{g}\end{array}$ & $\begin{array}{c}\text { from } \\
1 \\
\text { bush, } \\
\text { g }\end{array}$ & & $\begin{array}{c}\text { averag } \\
\text { e mass, } \\
\text { g }\end{array}$ & t/ ha \\
\hline \multicolumn{9}{|c|}{ Medium fraction } \\
\hline 10 & 96 & 90 & 3,05 & 2,70 & 8,25 & 801 & 38 & 9,3 \\
\hline 15 & 98 & 96 & 3,17 & 2,77 & 8,76 & 921 & 37 & 9,8 \\
\hline 20 & 97 & 94 & 3,25 & 2,75 & 8,93 & 918 & 28 & 8,1 \\
\hline $\mathrm{HCP}_{05}$ & & & & 0,25 & 0,46 & 89 & & \\
\hline \multicolumn{9}{|c|}{ Small fraction } \\
\hline 10 & 95 & 91 & 2,32 & 2,80 & 6,47 & 661 & 33 & 8,7 \\
\hline 15 & 98 & 96 & 2,56 & 2,92 & 7,15 & 799 & 26 & 8,0 \\
\hline 20 & 97 & 93 & 2,55 & 3,04 & 7,81 & 792 & 18 & 4,1 \\
\hline $\operatorname{LSD}_{05}$ & & & & 0,18 & 0,51 & 71 & & \\
\hline
\end{tabular}

When planting to a depth of $10 \mathrm{~cm}$, the seed yield from the plant is less due to the lesser number of surviving shooters on the plant and their productivity. Seed productivity is greater when planting bulbs to a depth of $15-20 \mathrm{~cm}$, where $2-6 \%$ more harvested plants. The seed productivity of the seedstalk mainly depended on the size of mother bulbs, the proportion of influence being on average $42 \%$ over three years. Plant productivity was more influenced by planting depth due to lodging of seedstalks. The share of the effect of planting depth on the productivity of one plant was $44 \%$. The yield of seeds per hectare depended as much as possible on the depth of planting. The influence of this factor accounted for $45 \%$. The effect of the interaction of two factors on the size of planting material and planting depth on all productivity indicators for three years is $50 \ldots 53 \%$ (fig. $3)$. 


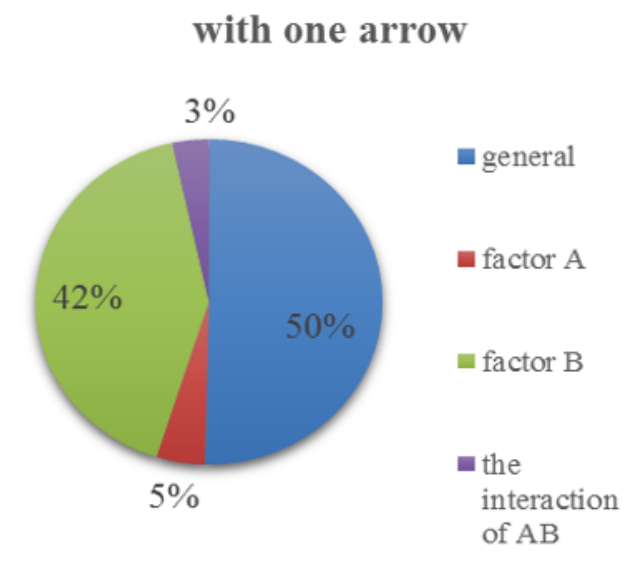

from one bush
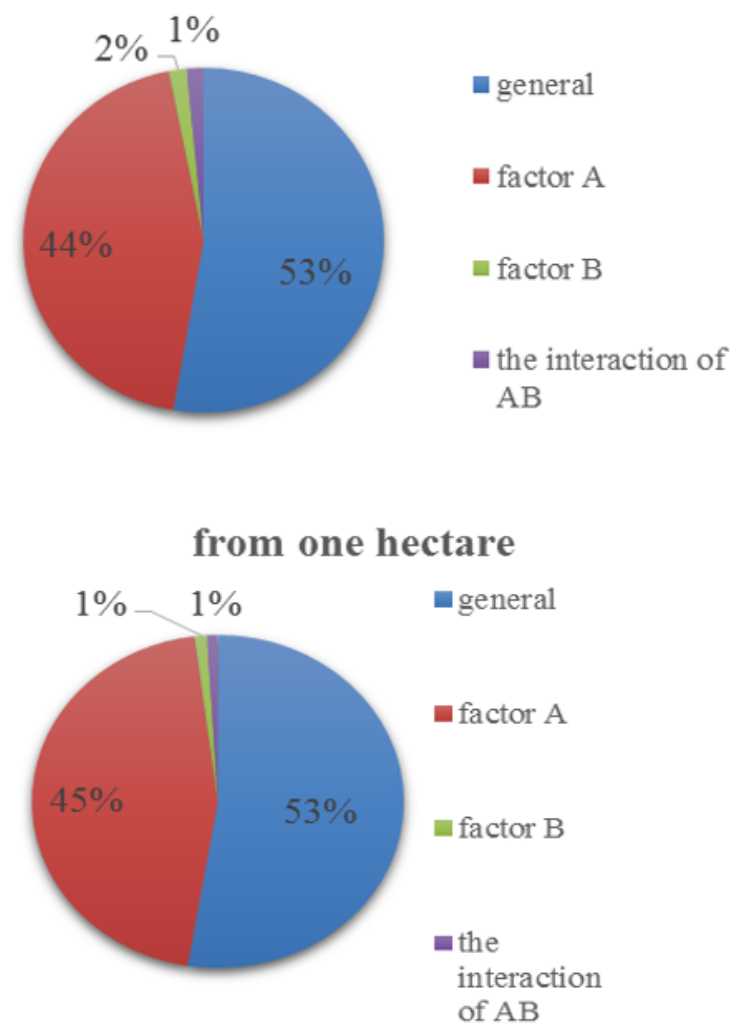

Fig. 3. The share of the influence (contribution) of each type of variability on the formation of seed productivity of onion mother bulbs. Factor A - planting depth; factor B - bulbs fraction.

By the end of the growing season, large bulbs near the seeds talks were formed in the seed plants of the winter variety Ellan, the mass of which decreased with the depth of planting. In plants from the medium fraction, the size of the bulbs decreased from 38 to 28 $\mathrm{g}$, in the small fraction from 33 to $18 \mathrm{~g}$. From a hectare, the yield of small-shoot bulbs in 
the medium fraction was $9.8 \ldots 8.1 \mathrm{t}$, in the small fraction $8.7 \ldots 4,1 \mathrm{t}$, fully compensating for the volume required for laying the seed production plot.

Despite the fact that with an increase in the depth of planting, the initial phases of growth were delayed, the seeds ripened simultaneously. In plants from medium bulbs, the number of inflorescences with open bolls on the day of harvest was $26.5 \ldots 29.2 \%$. There were fewer plants from the small fraction of bulbs with open bolls $-20.4 \ldots 24.5 \%$ (table 8). Regardless of the size of the bulbs and the depth of planting, the moisture of the seeds during harvesting varied slightly from 46 to $49 \%$ in 2003 and from 40 to $46 \%$ in 2004 . The sowing qualities of seeds in the variants did not differ much. The absolute weight of 1000 seeds grown from medium bulbs is $3.76 \ldots 3.84 \mathrm{~g}$, from small bulbs $3.92 \ldots 4.05 \mathrm{~g}$. For all variants of the experiment, the seeds had high germination energy (74 .. 77\%) and germination $(92 \ldots 96 \%)$.

Table 8. Onion seed quality at different planting depths.

\begin{tabular}{|c|c|c|c|c|c|c|c|}
\hline $\begin{array}{c}\text { Planting } \\
\text { depth, cm }\end{array}$ & $\begin{array}{c}\text { Seed } \\
\text { moisture } \\
\text { during } \\
\text { harvesting, } \\
\%\end{array}$ & $\begin{array}{c}\text { Moisture of } \\
\text { seeds and } \\
\text { bolls during } \\
\text { harvesting, } \\
\%\end{array}$ & $\begin{array}{l}\text { The number } \\
\text { of } \\
\text { inflorescences } \\
\text { with open } \\
\text { bolls, \% }\end{array}$ & $\begin{array}{c}\text { Mass } \\
\text { of } \\
1000 \\
\text { seeds, } \\
\text { g }\end{array}$ & $\begin{array}{c}\text { Viability, } \\
\%\end{array}$ & $\begin{array}{c}\text { Germination } \\
\text { ability, \% }\end{array}$ & $\begin{array}{c}\text { Yield } \\
\text { properties, } \\
\text { c/ha }\end{array}$ \\
\hline \multicolumn{8}{|c|}{2003} \\
\hline \multicolumn{8}{|c|}{ Medium fraction } \\
\hline 10 & 48.2 & 63 & 39.2 & 3.76 & 74 & 94 & 110 \\
\hline 15 & 47 & 62.7 & 36.5 & 3.84 & 77 & 92 & 113 \\
\hline 20 & 45.6 & 64.2 & 39.2 & 3.8 & 75 & 95 & 114 \\
\hline \multicolumn{8}{|c|}{ Small fraction } \\
\hline 10 & 46.6 & 65.1 & 25.7 & 3.96 & 76 & 95 & 112 \\
\hline 15 & 49.2 & 65.9 & 30.4 & 4.05 & 75 & 93 & 114 \\
\hline 20 & 46.2 & 66.1 & 26.8 & 3.92 & 78 & 96 & 113 \\
\hline \multicolumn{8}{|c|}{2004} \\
\hline \multicolumn{8}{|c|}{ Medium fraction } \\
\hline 10 & 40.2 & 61 & 32 & 3.52 & 76 & 96 & 216 \\
\hline 15 & 43.7 & 61.4 & 28.3 & 3.6 & 78 & 96 & 222 \\
\hline 20 & 44.6 & 70.2 & 30 & 3.58 & 78 & 97 & 220 \\
\hline \multicolumn{8}{|c|}{ Small fraction } \\
\hline 10 & 41.5 & 66.2 & 30.7 & 3.61 & 78 & 95 & 220 \\
\hline 15 & 46.8 & 65.6 & 28.9 & 3.72 & 80 & 94 & 218 \\
\hline 20 & 45.5 & 62.2 & 30.6 & 3.68 & 77 & 96 & 229 \\
\hline
\end{tabular}

\section{Conclusions}

An analysis of the research results showed that in order to increase winter hardiness and eliminate losses from adverse winter conditions, it is necessary to plant mother bulbs to a depth of $15 \mathrm{~cm}$. With shallow planting $(10 \mathrm{~cm})$, the bulbs freeze. Planting to a depth of 20 $\mathrm{cm}$ is difficult, especially for weakened bulbs, which leads to restraint of their growth and development. Some plants cannot grow from this depth.

To maintain the vertical position of the shooter without additional hilling, it is necessary to plant mother bulbs to a depth of $15 \mathrm{~cm}$. With this depth of planting, the soil layer above the bulb holds and prevents the seedstalks from deflecting naturally.

With a shallow planting to a depth of $10 \mathrm{~cm}$, the flower stalks fall apart, intertwine with adjacent rows, fall and often sink to the ground. Insects do practically not pollinate inflorescences lying on the ground, which leads to a loss of seed yield. The ventilation of 
the rows and the phytosanitary condition of plants are significantly deteriorating. In such areas, it is difficult to carry out agricultural activities and harvest.

\section{References}

1. Tkhamokov Z D 2012 Works of the Kuban State Agrarian University 5(38) 86-90

2. Litvinov S S 2011 Methodology of experiments in vegetable growing (Moscow) p 648

3. Moisevich N V 2009 Onion seed production Biology, agricultural technology, economics: monograph (Minsk: Printing House "VLA") p 144

4. Gish R A 2004 Actual problems and ways to solve them in modern fruit growing, vegetable growing and viticulture of the Don: materials of scientific-practical. Conf. (Krasnodar) pp 98-101

5. Lazko V E 2009 Collection of scientific works Problems of scientific support of vegetable growing in the South of Russia ed V N Samodurov (Krasnodar) pp 121-122

6. Lazko V E 2009 Collection of scientific works Problems of scientific support of vegetable growing in the South of Russia ed V N Samodurov (Krasnodar) pp 113-120

7. Lazko V E Collection of scientific works Problems of scientific support of vegetable growing in the South of Russia ed V N Samodurov (Krasnodar) pp 105-112

8. Ludilov V A 2005 Seed science of vegetable and melon crops (Moscow: Federal State Institution "Rosinforagroteh") p 392

9. Sheudzhen A Kh 2013 Agrochemical basis for the use of fertilizer (Maikop: JSC Polygraph-Yug) p 572

10. Dzuba V A 2010 The theoretical and applied of plant growing: for example wheats, barley and rice (Krasnodar) p 475

11. Dzuba V A 2007 Multivariate experiments and methods of biometric analysis of experimental data (Krasnodar) p 76

12. Sheudzhen A Kh 2015 Methodology of agrochemical research and statistical evaluation of their results: textbook 2nd ed revised and completed (Maykop: OJSC "Polygraph-South") p 664

13. Lazko V E 2008 Handbook of the Kuban vegetable grower (Krasnodar: Council Kuban) pp 90-94

14. Lazko V E 2008 Vegetable growing: collection of scientific books RUE Institute of Vegetable Production vol 14 (Minsk) pp 233-240

15. Lazko V E 2005 Features of seed production of winter onion variety Ellan in the conditions of the Western Ciscaucasia: Abstract of Ph.D. thesis: 01/06/05 (Kuban State Agrarian University Krasnodar) p 23 